\begin{tabular}{|c|c|c|c|c|c|}
\hline MUNIBE Antropologia-Arkeologia & $n^{\circ} 67$ & $167-183$ & DONOSTIA & 2016 & ISSN 1132-2217 • elSSN 2172-4555 \\
\hline
\end{tabular}

\title{
El castillo de Portilla (Zambrana, Álava). Origen y significado de una fortaleza plenomedieval en territorio alavés (siglos XI-XII)
}

\author{
Portilla Castle (Zambrana, Álava). Origins and meaning of a late-medieval \\ fortress in the territory of Alava (11th-12th centuries)
}

PALABRAS CLAVES: fuentes escritas, arqueología, feudalismo, castillo poblacional, poderes públicos y privados. GAKO-HITZAK: Idatzizko iturriak, arkeologia, feudalismoa, populazioaren gaztelua, botere publiko eta pribatuak. KEY WORDS: written sources, archaeology, feudalism, castle population, public and private power.

Jose Luis SOLAUN BUSTINZA ${ }^{(1)}$ \& Agustín AZKARATE GARAI-OLAUN(2)

\section{RESUMEN}

El Conjunto Monumental de Portilla puede catalogarse como un lugar histórico que brinda una oportunidad única a la hora de encarar un análisis integral de un paisaje cultural que atienda tanto a su estudio como a su puesta en valor. En esta ocasión se pondrá el acento en su castillo, un hito o punto de referencia visual para la población del entorno, para cuyo estudio tradicionalmente se ha recurrido de forma casi exclusiva al registro escrito.

Las recientes investigaciones arqueológicas efectuadas en esta fortaleza han permitido conocer mejor su origen y significado. Las evidencias apuntan a que la actual fortaleza, construida entre principios del siglo XI y mediados del siglo XII, estuvo bajo titularidad real, aunque fue gestionada por importantes aristocracias locales y regionales, siendo testigo de las complejas relaciones entre el poder público y privado y, obviamente, de la multiplicidad de funciones que esta fortaleza pudo desempeñar.

\section{LABURPENA}

Portilla Monumentu Multzoa leku historiko gisa kataloga daiteke; izan ere, paisaia kulturalaren azterketa integrala egiteko garaian aukera bikaina eskaintzen du, bai azterketa egiteko, bai balioa emateko. Oraingoan, gazteluan jarriko dugu arreta; inguruneko herritarrentzat erreferentzia bisuala eta mugarria da, eta tradizioz, hori aztertzeko ia modu esklusiboan idatzizko erregistrora jo izan da.

Gotorlekuan egindako azken ikerketa arkeologikoek ahalbidetu digute haren jatorria eta esanahia hobeto ezagutzea. Ebidentzien arabera, gaur egungo gotorlekua, XI. mende hasieraren eta XII. mende erdialdearen artean eraikitakoa, erregearen titulartasunaren pean egon zen, baina tokiko eta eskualdeko aristokrazia garrantzitsuek kudeatu zuten, eta botere publiko eta pribatuaren arteko harreman konplexuen lekuko izan zen baita, noski, gotorleku horrek izan zitzakeen funtzio ugarien lekuko ere.

\section{ABSTRACT}

The Monumental Ensemble of Portilla is a historic place that provides a unique opportunity for integrated study of a cultural landscape that provides both an analysis and an enhancement of its value. On this occasion, focus will be on the castle, which forms a visual milestone or point of reference for the surrounding population, and which, traditionally, has been studied almost exclusively on the basis of its written record.

Recent archaeological investigations carried out at the fortress have given us a better understanding of its origin and significance. The evidence suggests that the current fortress was built between the early 11 th century and the mid-12th century, and that it was under royal ownership, mainly that of the kingdom of Pamplona. This fact, however, does not imply that effective control of the castle was in the king's hands; rather, it was managed by powerful local and regional aristocrats, demonstrating the complex relationships between public and private powers.

With regard to its function, this fortress played several roles, though not always simultaneously. Rather, its function varied over the course of time, according to political, economic and social changes. We know that Portilla was linked to the defence of border areas. Up to the 13th century, the square at Portilla was a key part of border defence between Castille and Navarre, with political swings from one side to the other. However, Portilla was much more than a fortress. It also comprised a territory that included the ancient villa of Portiella. The nature and origin of the close ties between the castle and the population centre merit further research.

\footnotetext{
(1) Grupo de Investigación en Patrimonio Construido (GPAC). Universidad del País Vasco/Euskal Herriko Unibertsitatea. Centro de Investigación Lascaray Ikergune. Avda. Miguel de Unamuno, 3. Campus de Álava. 01006 Vitoria-Gasteiz. joseluis.solaun@ehu.es

(2) Grupo de Investigación en Patrimonio Construido (GPAC). Universidad del País Vasco/Euskal Herriko Unibertsitatea.
} 


\section{1.- INTRODUCCIÓN}

El Conjunto Monumental de Portilla se sitúa en el municipio de Zambrana, en el extremo suroeste del Territorio Histórico de Álava (Figura 1). Su posición entre escarpados riscos, en la ladera Norte del monte Txulato, hacen de este enclave un lugar poco conocido y transitado, a pesar de encontrarse relativamente próximo a las principales vías de comunicación del valle. Es precisamente este carácter abrupto y elevado, el que explica su origen como plaza fuerte, plasmado incluso en su topónimo "Portilla" o "Zabalate" (= paso hacia terreno abierto).

Aunque el lugar se ha identificado tradicionalmente con el "castillo de Portilla", se trata de un sitio histórico de connotaciones más amplias y complejas, poseedor de una gran riqueza patrimonial, en su acepción más integral, tanto natural como cultural. El conjunto cuenta con unas espectaculares formaciones geológicas de estratos calizos verticales (sin las cuales no se podría comprenderse la naturaleza defensiva del enclave), un característico biotopo de transición entre los climas atlántico, mediterráneo y continental), un impresionante percepción del entorno, al localizarse en una atalaya con un gran dominio visual de prácticamente 360 grados sobre el territorio y, por supuesto, un importante patrimonio edificado, cuyos elementos más "visibles" se corresponden con el conjunto fortificado que componen el castillo y la antigua villa de Portiella, popularmente conocida como Villavieja.

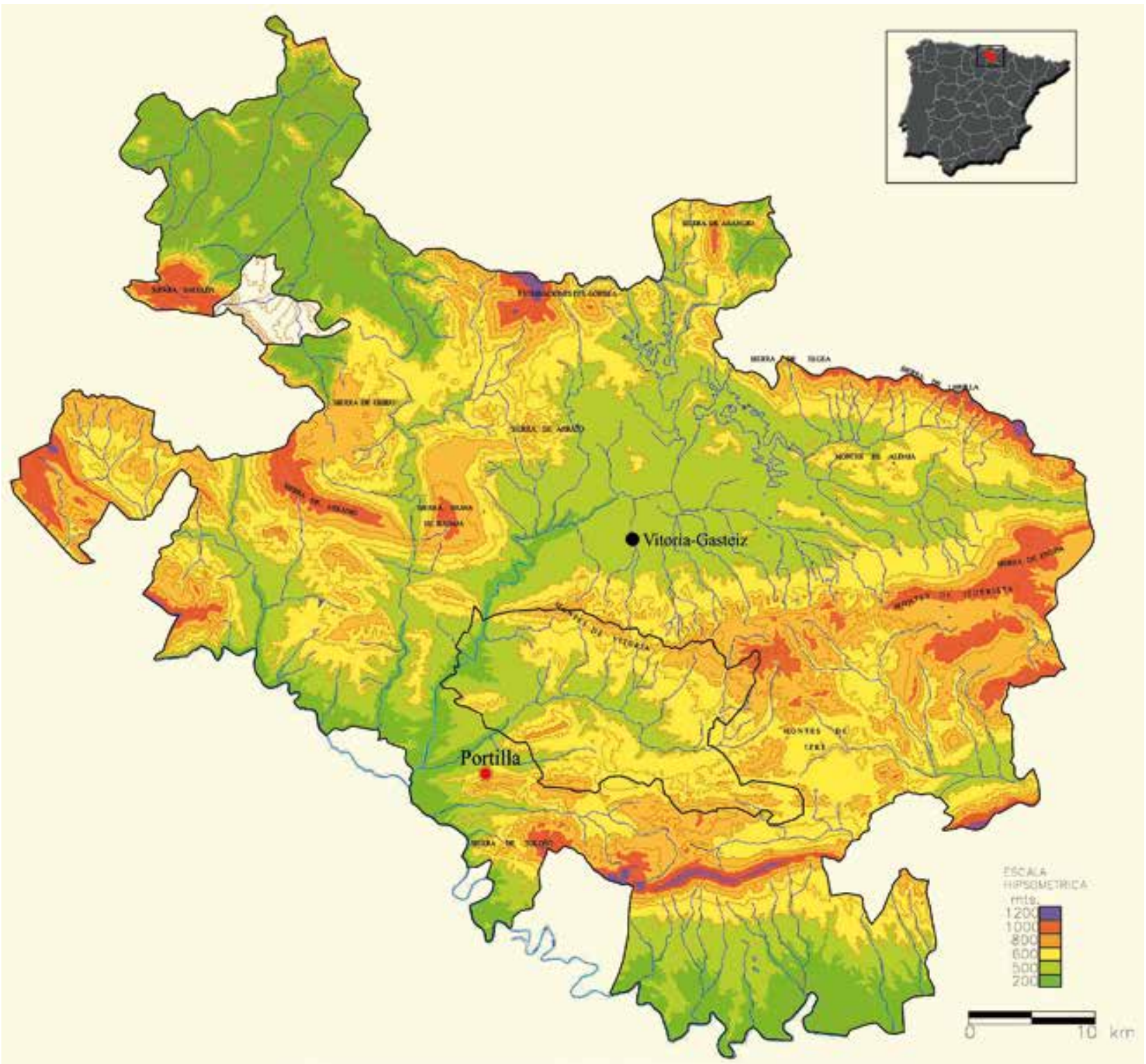

Fig. 1. Mapa de situación del lugar de Portilla (Zambrana, Álava). / Map of Portilla's location (Zambrana, Álava). 
intervenciones arqueológicas efectuadas en el castillo y las murallas de la Villavieja, y cuyo objetivo principal atendía a la necesidad de "conocer" bien el lugar como paso previo a "intervenir" en él. En esta ocasión nos centraremos en los resultados históricos generados de este proceso, relacionados sin duda con las investigaciones que, desde nuestro Grupo de Investigación, se vienen llevando a cabo en relación con la configuración del poblamiento altomedieval y la arquitectura defensiva.

\section{EL CASTILLO}

Como señalamos anteriormente, la intervención arqueológica efectuada en Portilla estuvo condicionada por los trabajos arquitectónicos que debían acometerse en el conjunto fortificado (Figura 2); en concreto, la construcción de una pasarela de acceso al castillo

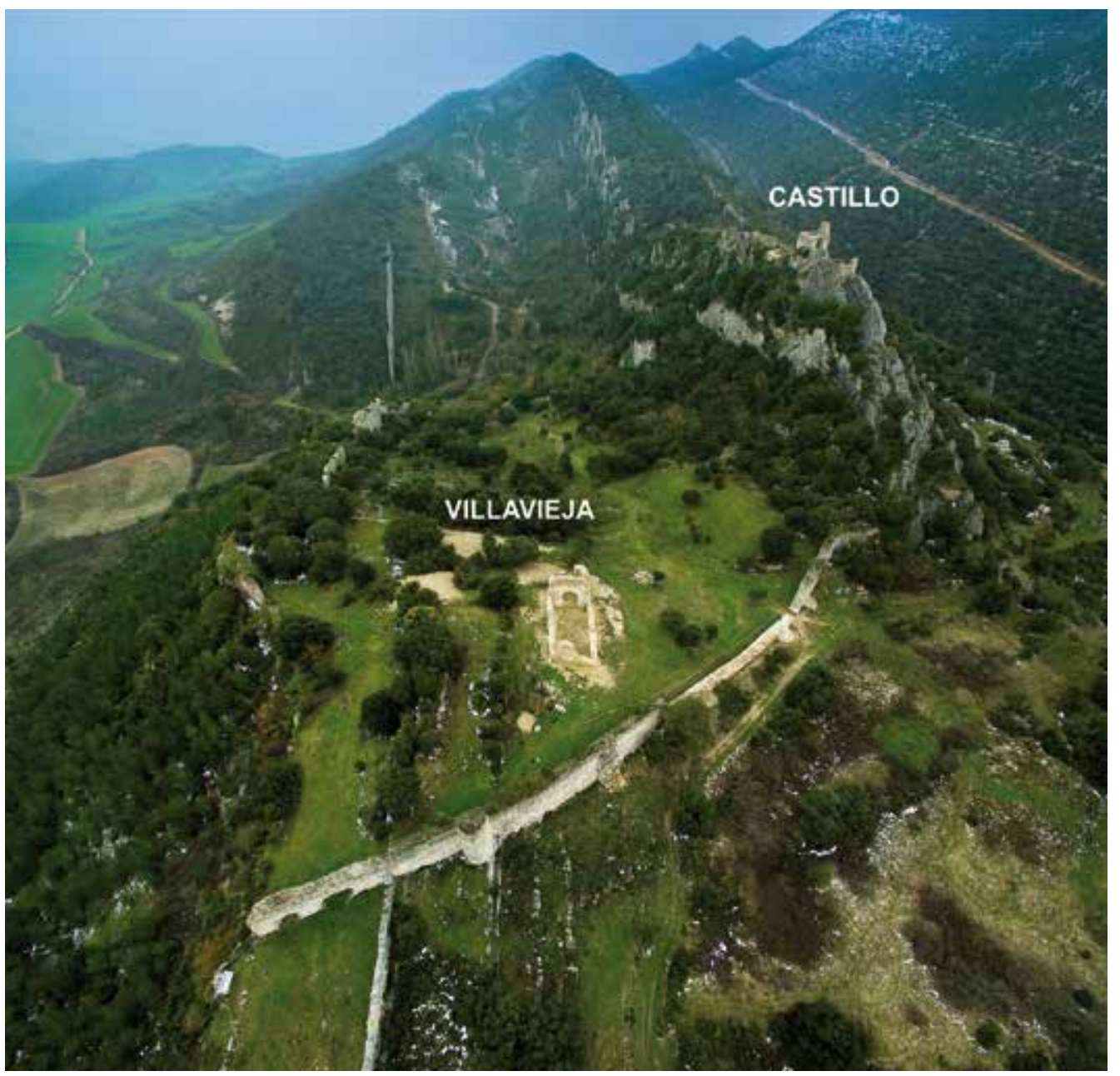

Fig. 2. Vista aérea del conjunto fortificado de Portilla/ Aerial view of the fortified complex of Portilla.

\footnotetext{
${ }^{1}$ El proyecto de recuperación del Conjunto Monumental de Portilla ha sido distinguido recientemente con el premio Hispania Nostra 2016 en su categoría de "Intervención en el Territorio o en el Paisaje".

2 Desde mediados del siglo XX se han desarrollado en el yacimiento de Portilla diversas actuaciones arqueológicas, cuya síntesis fue publicada por Javier Fernández Bordegarai (2007: 409-410).
} 
y la recuperación de un tramo de la muralla alta de la Villavieja. No obstante, esta actuación tuvo también un carácter valorativo, en tanto permitía evaluar las posibilidades de un lugar que había sido objeto de intervenciones arqueológicas previas con diversos resultados . Los datos que se presentan en este capítulo son, por tanto, un avance de resultados de naturaleza básicamente descriptiva y como tal deben entenderse hasta que no avancen las investigaciones del lugar.

\subsection{Su configuración espacial}

El castillo de Portilla se sitúa sobre una abrupta peña de 780 metros de altitud, estrecha y alargada, que le proporciona una característica planta barquiforme. En la cumbre y sus inmediaciones se pueden observar múltiples estructuras que reflejan la compleja articulación poliorcética de una fortaleza indudablemente singular, organizada en tres niveles diferentes (Figura 3).
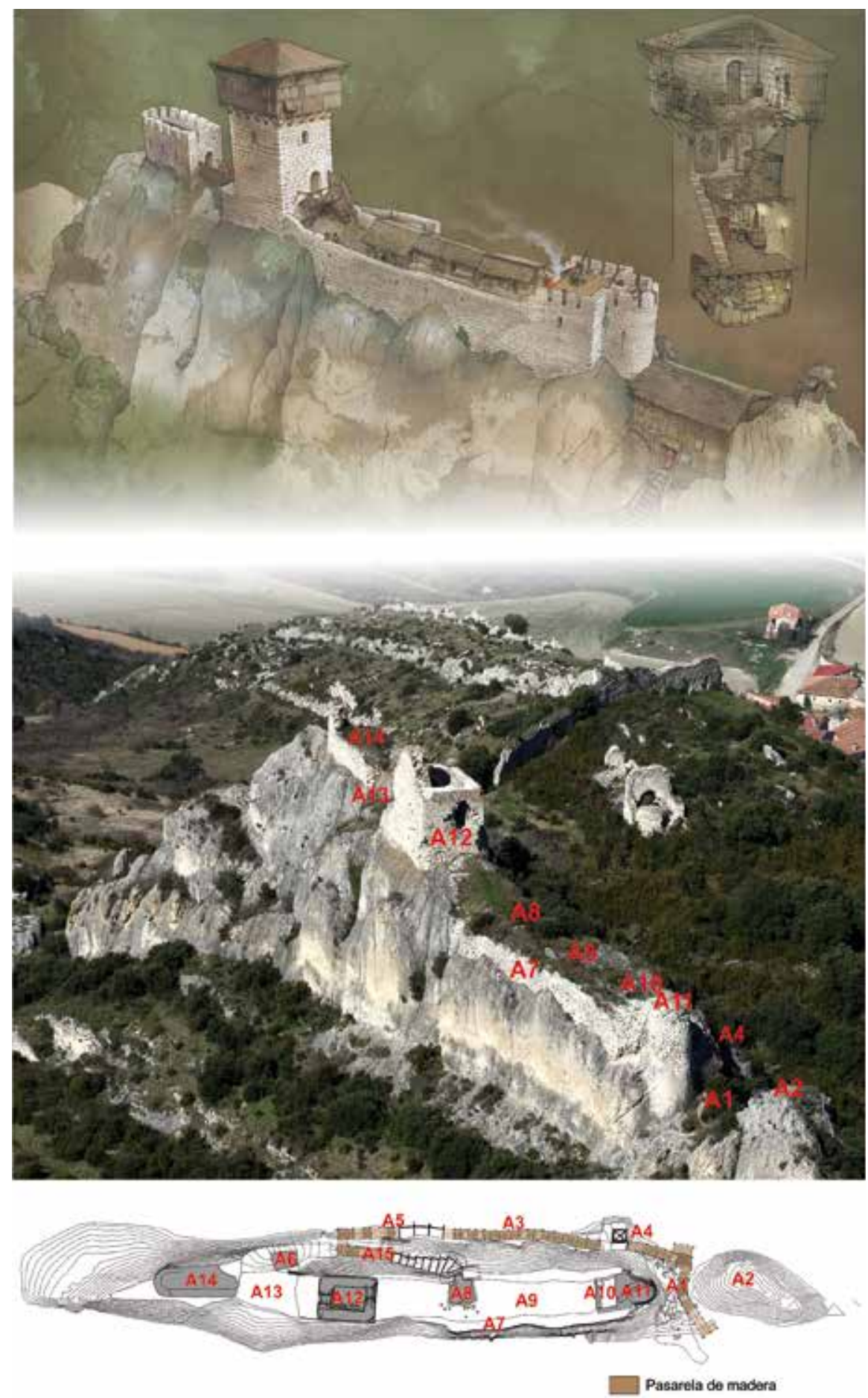

Fig. 3. Recreación, imagen aérea y planta del castillo de Portilla antes del proceso de excavación, con la situación de las diferentes estructuras mencionadas en el texto. / Reproduction, aerial image and ground plan of Portilla before the excavation process, with the locations of structures mentioned in the text. 


\subsubsection{El nivel inferior}

- Puerta Sur (A1). Tomando el camino que desde la Villavieja se dirige al castillo por el Sur, nos topamos con el frente meridional de un imponente farallón rocoso sobre el que se alza la fortaleza de Portilla. En su extremo oriental se abre un pequeño collado, ocupado en su día por un gran edificio lígneo que funcionó como cuerpo de guardia del acceso al castillo por este costado. Numerosos mechinales y entalladuras abiertos en la roca denuncian la existencia de pies derechos, durmientes y cuantos elementos conforman estas arquitecturas de madera (Figura 4a). Las dimensiones de estos testimonios apuntan a una importante construcción que daría acceso también a una garita de vigilancia levantada sobre el escarpe oriental (A2).

- Garita de vigilancia (A2). Sobre el cabezo oriental se situaba un pequeño torreón de vigilancia del que apenas conservamos el arranque de su cimentación, cajeada en la roca. Aunque la intervención arqueológica no se extendió hasta este espacio, todo apunta a que nos encontramos ante una garita similar a la que describiremos en A4.

- Pasillo inferior (A3). Al noreste de A1 nacía un estrecho pasillo o corredor que recorría el farallón por su cara septentrional, hasta comunicar con una posible puerta por el Norte. Su técnica constructiva, orientada a ganar espacio útil al farallón rocoso, era sencilla pero efectiva. Los constructores comenzaron tallando en la roca un estrecho pasillo de un metro de anchura y apenas dos de longitud, defendido por una pequeña torre de control (A4) (Figura 4b). Desde este punto en adelante, donde el farallón no permitía una anchura adecuada de paso, se labró la roca a una cota inferior (en ocasiones a más de un metro de profundidad), cajeándola escalonadamente y levantando sobre las camas creadas a tal efecto un muro de mampostería corrido. Este muro, junto con el propio farallón rocoso, contenían un relleno interior de tierra y piedra que conformaba un pasillo de aproximadamente 1,5 metros de anchura y 33 metros de longitud.

- Garita de control (A4). Como ya indicamos, al inicio del pasillo se levantaba una garita de control de la que solo conservamos los cajeados de su base, de planta cuadrangular (2,4 × 2,1 metros), destinados a alojar los zócalos de piedra, sobre los que cabe imaginar alzados perecederos de madera (Figura 4b).

- Puerta Norte (A5). En su parte final, el pasillo comunicaba con otro camino que, desde la Villavieja, ascendía sinuosamente hacía el castillo. Ambos caminos convergían en una estructura en rampa, actualmente desmantelada, construida con un característico aparejo de sillarejo, de mediano y gran tamaño, que en adelan- te denominaremos "Tipo 1"3 (Figura 4c). Aunque en la actualidad no se conservan evidencias de una puerta de acceso y control en este punto, la lógica poliorcética apunta a su posible existencia, habilitada tanto para el tráfico de personas como de caballería ${ }^{4}$.

\subsubsection{El nivel intermedio}

- Terraza intermedia (A15). A través de la estructura antes descrita (A5) se accedía a la terraza intermedia del complejo defensivo, desde donde se habilitaba el acceso al recinto superior mediante un recorrido en zigzag. Su técnica constructiva era similar a la del pasillo inferior. En esta ocasión, los constructores tallaron la roca a la cota del corredor inferior, levantando sobre las entalladuras una muralla (con aparejo del Tipo 1, igual al de la puerta norte) que, junto al relleno interior, acabó conformando una terraza de aproximadamente 22 metros de longitud por 3 metros de anchura.

- Aljibe (A6). Emplazado en el extremo oriental de esta misma terraza, se situaba el aljibe de la fortaleza, de planta rectangular. Se trata de una estructura excavada parcialmente en la roca, cubierta por una bóveda rebajada de lajas calizas, en cuyo remate se abría un orificio cenital que permitía la recogida del agua de lluvia (Figura 4d). El sistema de recogida era sencillo, pero eficiente. El aljibe aprovechaba la ligera inclinación que presentaba el suelo del foso (A8) hacia el Norte para conducir el agua de lluvia hasta su cubierta. Sus paredes estaban impermeabilizadas con pintura roja a la almagra.

Atendiendo a sus dimensiones, de 3,4 metros de longitud por 2 metros de anchura máxima y más de 3 metros de altura (en la actualidad todo el interior se encuentra colmatado por diversos aportes de tierra y el propio escombro de la bóveda, lo que impide apreciar la profundidad total del vaso), permitiría un volumen aproximado de 20.000 litros de agua.

\subsubsection{El nivel superior}

- Plataforma superior (A7). La "zona alta" de la fortaleza acogía las principales estructuras defensivas, productivas y residenciales del castillo, todas ellas levantadas sobre un peñón alargado de paredes muy pronunciadas. Los trabajos de acondicionamiento comenzaron con la labra del peñón ${ }^{5}$, destinada a enfatizar su verticalidad y mejorar así su defensa. La escasa superficie de la peña obligó también a la construcción de un muro perimetral, repitiendo modelos ya documentados en otras fortalezas del entorno, como por ejemplo Peña del Castillo en Marquinez (Álava) (AZKARATE, SOLAUN,

\footnotetext{
3 Más adelante, al abordar el capítulo "1.2. Su construcción", incidiremos en la especificidad de este aparejo.

${ }^{4}$ Una estructura formalmente similar puede reconocerse en el vecino castillo de Ocio, que daba acceso a la fortaleza por la ladera Norte (Sánchez, Solaun, 2003).

5 Todo apunta además a que el peñón fue utilizado previamente como cantera (calizas danienses), según se desprende del estudio geológico efectuado por L.M. Martínez Torres (2014).
} 

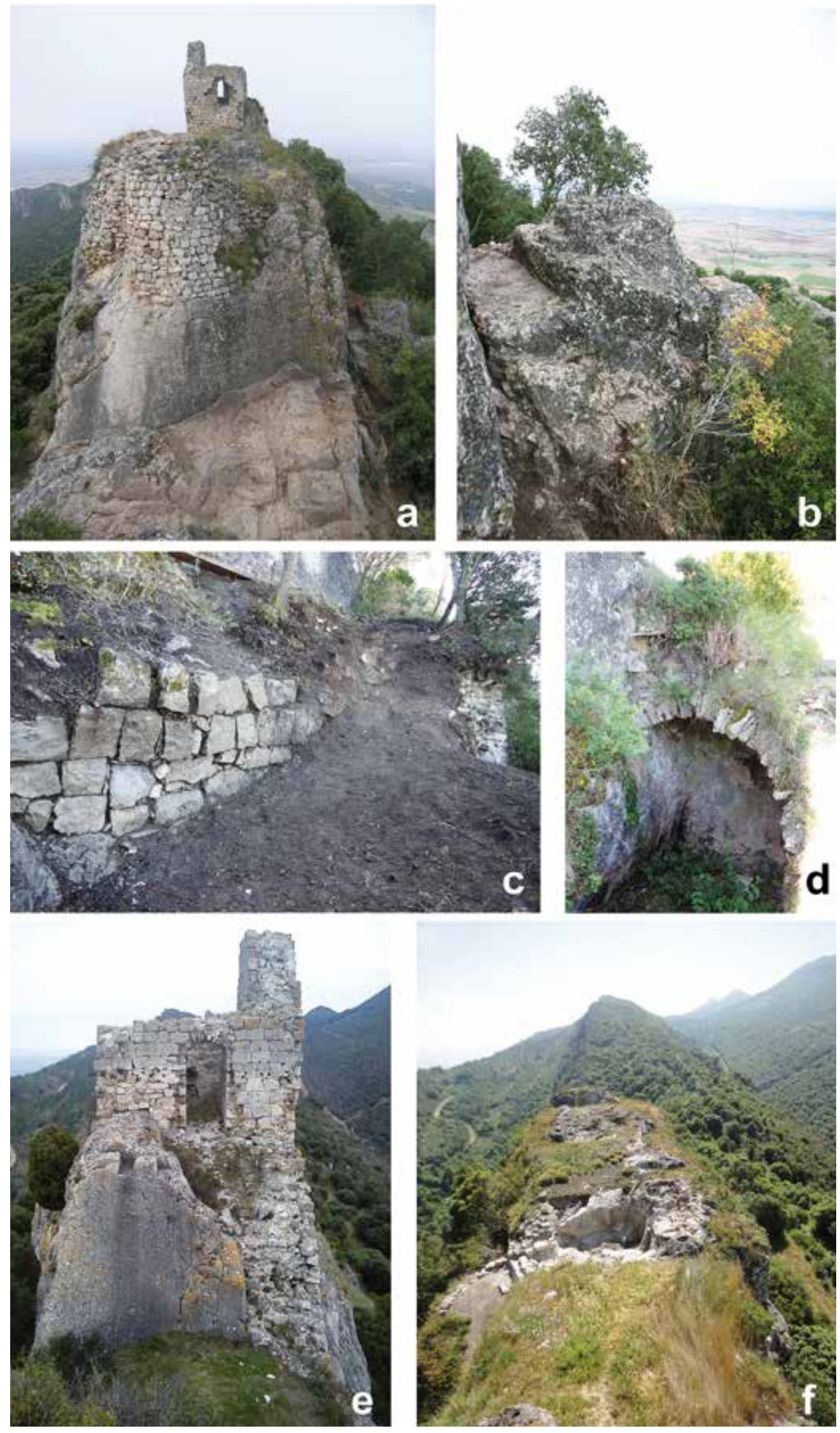

Fig. 4. a) Imagen de los entaIles abiertos en el suelo de A1, bajo el torreón oriental $A 11 ;$ b) Pasillo inferior excavado en roca y base de la garita de vigilancia A4; c) Imagen, durante el proceso de excavación de la posible ubicación de la puerta norte (A5); d) Aljibe A6; e) Imagen del foso A13 y de la torre del homenaje A12; f) Vista, desde la torre del homenaje, de la plataforma superior, con el cuerpo de guardia A8 en primera instancia. / a) Image of exposed carvings in the floor of $A 1$, under the eastern tower A11; b) Lower passage excavated in rock and base of watchtower A4; c) Image of the possible location of the northern door, taken during excavation; d) Cistern A6; e) Image of moat $A 13$ and the keep A12; f) View from the keep of the upper platform, with guardhouse $\mathrm{A} 8$ in the foreground. 
2008). Para ello se procedió al cajeado de la roca en su remate superior, careando después con mampostería todo el contorno hasta conformar un muro de entre 1,5 y 2 metros de grosor, en el que se detectan numerosos cambios de fábrica provocados por las múltiples refacciones efectuadas ${ }^{6}$.

El espacio generado, una vez construidos los muros perimetrales, permitió que los usuarios de la fortaleza dispusieran de una plataforma superior de aproximadamente 60 metros de longitud por 7 ó 8 metros de anchura (Figura 4f).

- Cuerpo de guardia (A8). La única entrada al recinto superior se realizaba por el Norte, a través de una estancia situada en posición central, de planta cuadrangular ( $3 \times 3,2$ metros) y parcialmente excavada en la roca $^{7}$. Dos escalones de piedra conformaban su umbral de ingreso, de 1,1 metros de luz. Su interior debió disponer de un suelo de madera en suspensión que cubría la roca, cuyo empleo, documentado en otros contextos domésticos del entorno (AZKARATE, SOLAUN, 2012: 123), permitiría disfrutar de un suelo confortable, aislado frente a posibles humedades.

Esta estancia, situada en posición central, constituía en realidad un vestíbulo de control y distribución, ya que articulaba el paso hacia el resto de estructuras situadas al Este y Oeste de la fortaleza (Figura 4f).

La presencia de numerosos agujeros de poste en el perímetro exterior de la estancia denuncia además la existencia de un alzado superior lígneo, compuesto muy probablemente por un armazón de postes cerrados con tablazón de madera, dado que no se han hallado restos de adobe, ladrillo o arcilla que denuncien el empleo de otras técnicas constructivas, como el pan de bois ${ }^{8}$ o el clayonnage ${ }^{9}$. La ausencia de teja en los rellenos que amortizaban esta habitación, apuntan asimismo a techumbres construidas con ramajes vegetales o tablillas de madera.

Su excavación ha ofrecido datos sumamente interesantes de carácter constructivo y cronológico, como tendremos ocasión de comprobar más adelante. Queremos señalar aquí que la aparición de media docena de proyectiles (bolaños) de trabuquete o pierrière, concentrados en los rellenos de amortización de esta estancia, permite suponer la presencia de este tipo de ingenios militares en el interior del recinto fortificado, muy posiblemente en las torres de oriente y/o poniente.

- Edificios auxiliares (A9). En el espacio situado entre el cuerpo de guardia y la fragua $A 10$, se documentan numerosos agujeros abiertos en la roca destinados a alojar diversas estructuras lígneas de las que, en el estado actual del conocimiento, desconocemos su naturaleza y dimensiones. Quizás, atendiendo al resto de actividades registradas, pudieron funcionar como espacios de almacén, cocina o dormitorio para la guarnición.

- Fragua (A10). En el extremo oriental del recinto superior se sitúa una nueva estancia cuya planta será nuevamente resultado de la combinación ya conocida de retalle de la peña y levante de fábrica. Puede observarse, en efecto, cómo sus lados Norte y Oeste se tallaron en la roca, haciendo de pared, mientras que al Sur y Este (y parcialmente en su extremo suroeste) se levantaron sendos muros con aparejo Tipo 1. De todo ello resultó una estancia rectangular de 3,5 metros de longitud por 2,5 metros de anchura. En el ángulo noroeste se conservaban además los restos de una estructura cuadrangular sobreelevada, perteneciente quizás a un apoyo.

Las excavaciones efectuadas en el año 1991 (FERNANDEZ BORDEGARAI, 1991) permitieron registrar también una oquedad abierta en la base del muro oriental, con bóveda de horno, de funcionalidad metalúrgica. Este horno se encontraba asociado a dos suelos superpuestos de coloración negruzca, en uno de los cuales se encontraron cinco clavijas córneas de mamífero (cuyas astas son comúnmente utilizadas como mangos de cuchillos) que permiten asociar la estancia con un pequeño taller metalúrgico destinado a la fabricación de este tipo de útiles.

- Torreón oriental (A11). En el extremo oriental del recinto superior se levanta un torreón semicircular que remata la fortaleza por este costado, protegiendo la puerta Sur A1. Se trata de una estructura maciza de aproximadamente 3,9 x 3,5 metros de planta, en la actualidad muy derruida, que debió contar con una plataforma de vigilancia, prolongada muy posiblemente hacia el Oeste mediante un entarimado lígneo que haría las veces de cubierta de la fragua

- Torre del homenaje (A12). A pesar del deficiente estado de conservación de la torre del homenaje, causado fundamentalmente por los continuos expolios sufridos, es la estructura de fábrica que mayor alzado conserva del castillo.

La torre se asienta sobre un escarpe rocoso que exigió, una vez más, ampliar la escasa superficie útil de la roca. Para ello se empleó la misma técnica constructiva que describimos en ocasiones anteriores, resultando un edificio rectangular de 7,5 metros de longitud por 5,8 metros de anchura, y muros de 1,4 metros de espesor. Su aparejo, constituido por grandes sillarejos y sillares esquineros de caliza dolomítica labrados a cincel y ta-

\footnotetext{
${ }^{6}$ Se trata de múltiples arreglos que, debido a su complicada identificación y delimitación, no permiten ser considerados como fases constructivas. ${ }^{7}$ Es lógico suponer que la excavación en el terreno de esta estructura fue realizada por razones defensivas, ya que permitiría una adecuada protección frente a los ataques exteriores con proyectiles de trabuquete.

8 Técnica constructiva consistente en un armazón de postes verticales y codales horizontales encajados, que genera sólidos paneles cuadrados o rectangulares rellenados por arcilla, adobes o ladrillos.

9 Técnica constructiva consistente en un esqueleto de ramas entrecruzadas manteadas con arcilla.
} 
llante, corresponde nuevamente al Tipo 1, encontrándose parcialmente recubierto por un enfoscado de color ocre (Figura 4e).

Sus alzados permiten definir la presencia de, al menos, tres plantas. El sótano, completamente colmatado por efecto de la ruina del edificio, parece corresponderse con una bodega subterránea excavada parcialmente en la roca. La planta baja presenta, por su parte, una superficie interior de $12 \mathrm{~m}^{2}$ y 4 metros de altura, con sendos ingresos enfrentados al Este y Oeste. Aunque su dovelaje se encuentra expoliado, todo apunta a puertas con arcos de medio punto. El acceso oriental, de 1,15 x 2,60 metros, se situaba a unos 2 metros de altura con respecto al suelo de la plataforma $A 7$, cota que debió salvarse mediante una escalera de madera desaparecida. El occidental, por su parte, facilitaba el paso hacia el foso que pronto describiremos. Ambos conservan aún el hueco de las trancas de cierre. Adosando contra el muro Sur de esta primera planta se sitúa un estrecho patín de piedra de apenas 0,65 metros que ascendía al primer piso de la torre, del que aún se aprecian algunos mechinales de las vigas pertenecientes al forjado del suelo. Es probable que sobre este piso se situara una segunda altura, si bien ha desparecido por completo.

- Foso (A13). Inmediatamente al Oeste de la torre se abrió un foso de dimensiones notables, excavado cuidadosamente en la peña (Figura 4e). Sus paredes verticales presentan más de 4 metros de altura y una brecha de paso de aproximadamente 5 metros, reconociéndose la labra a picón o puntero. El remate de la roca aún conserva las entalladuras de apoyo de las traviesas del puente que salvaba el paso y facilitaba el acceso al torreón de poniente A14.

- Torreón de poniente (A14). A falta de una intervención arqueológica que determine con mayor exactitud su configuración, es posible avanzar que nos hallamos ante una última estancia aislada de la fortaleza por el foso, cuya planta va a ser producto del rebaje efectuado al sustrato rocoso, complementado con estructuras de fábrica y posiblemente madera. En concreto, se trata de una habitación semiexcavada en la peña, cerrada en su lado largo del Sur por un muro con aparejo del Tipo 1, que define una plataforma trapezoidal de 8,3 metros de longitud total y 2,70 metros de anchura máxima, rematada en su extremo por un torreón semicircular. Los alzados de este torreón aún conservan tres estrechas ventanas (0,5 metros de alto x 0,2 metros de luz), con dintel escalonado y fuerte derrame hacia el interior (0,86 metros de alto $\times 0,38$ metros de luz).

\subsection{Su construcción}

La lectura estratigráfica de alzados constituye una herramienta de análisis irreemplazable para conocer los orígenes y evolución constructiva de edificaciones históricas complejas. Pero su eficacia queda en entredicho en determinadas circunstancias: por ejemplo en las arquitecturas que fueron en origen de naturaleza lígnea y que no han dejado para la posterioridad materialidad alguna que vaya más allá de las improntas en negativo, en forma de agujeros, rozas o mechinales; también en aquellas otras que, siendo de fábrica, dificultan la observación de las relaciones de anteroposterioridad por la inexistencia de contacto físico entre las diversas estructuras; y, finalmente, en las arquitecturas rupestres en las que el paso del tiempo no se manifiesta por adición sino por sustracción de materiales (AZKARATE, 1997: 137). Las tres circunstancias descritas concurren en el castillo de Portilla, convirtiéndolo en un objeto de estudio particularmente complicado.

Afortunadamente, el Grupo de Investigación en Patrimonio Construido (GPAC) atesora una experiencia de varias décadas en las que la necesidad de hacer frente a circunstancias como las descritas ha permitido depurar nuevos sistemas de análisis. Nuestro grupo de investigación fue pionero, por ejemplo, en la combinación de dos sistemas de trabajo -en apariencia diferentes y considerados frecuentemente como antagónicos e incluso antitéticos- que se complementan (y se necesitan) entre sí. a) El primero de ellos - de naturaleza tipológica-, opera decodificando (deconstruyendo) las partes constitutivas de un edificio mediante la individualización de sus distintas variables para observar luego cómo se asocian entre sí hasta conformar conjuntos constructivos (clusters) de naturaleza sincrónica. b) El segundo -de carácter estratigráfico- analiza aquellos clusters que tienen relación física entre sí para descubrir, a través de sus interfaces, su ubicación en la secuencia constructiva del edificio; su naturaleza será, por tanto, diacrónica (AZKARATE, 2010: 55).

En el caso del castillo de Portilla solo resultaba posible el análisis tipológico, dado que la mayoría de las estructuras de fábrica están físicamente separadas entre sí. Sabíamos, con todo, que la individualización de variables tipológicas -como los aparejos, marcas de tallas- $u$ otras más de carácter arqueométrico -como las dataciones radiocarbónicas o los análisis de morteros- y la observación de sus relaciones podía ofrecer resultados interesantes.

El análisis de los aparejos no ofreció la variedad que en un principio cabía esperar. Su aparente diversidad en alguna zonas -como en la muralla perimetral de la plataforma superior- no era sino consecuencia de diversas reparaciones y refacciones acaecidas en el tiempo, limitándose el aparejo a un única variable (Tipo 1), caracterizada por el uso de sillarejo de mediano y gran tamaño, dispuesto en hiladas regulares (Figura 5$)^{10}$. Otra especificidad es la presencia de pe-

\footnotetext{
${ }^{10}$ Aunque el término sillarejo suele aplicarse al sillar pequeño con labra tosca (y, en nuestro caso, el módulo es de mediano y/o gran tamaño), hemos creído oportuno emplear este mismo vocablo, por tratarse de piezas labradas con una técnica similar al sillarejo.
} 

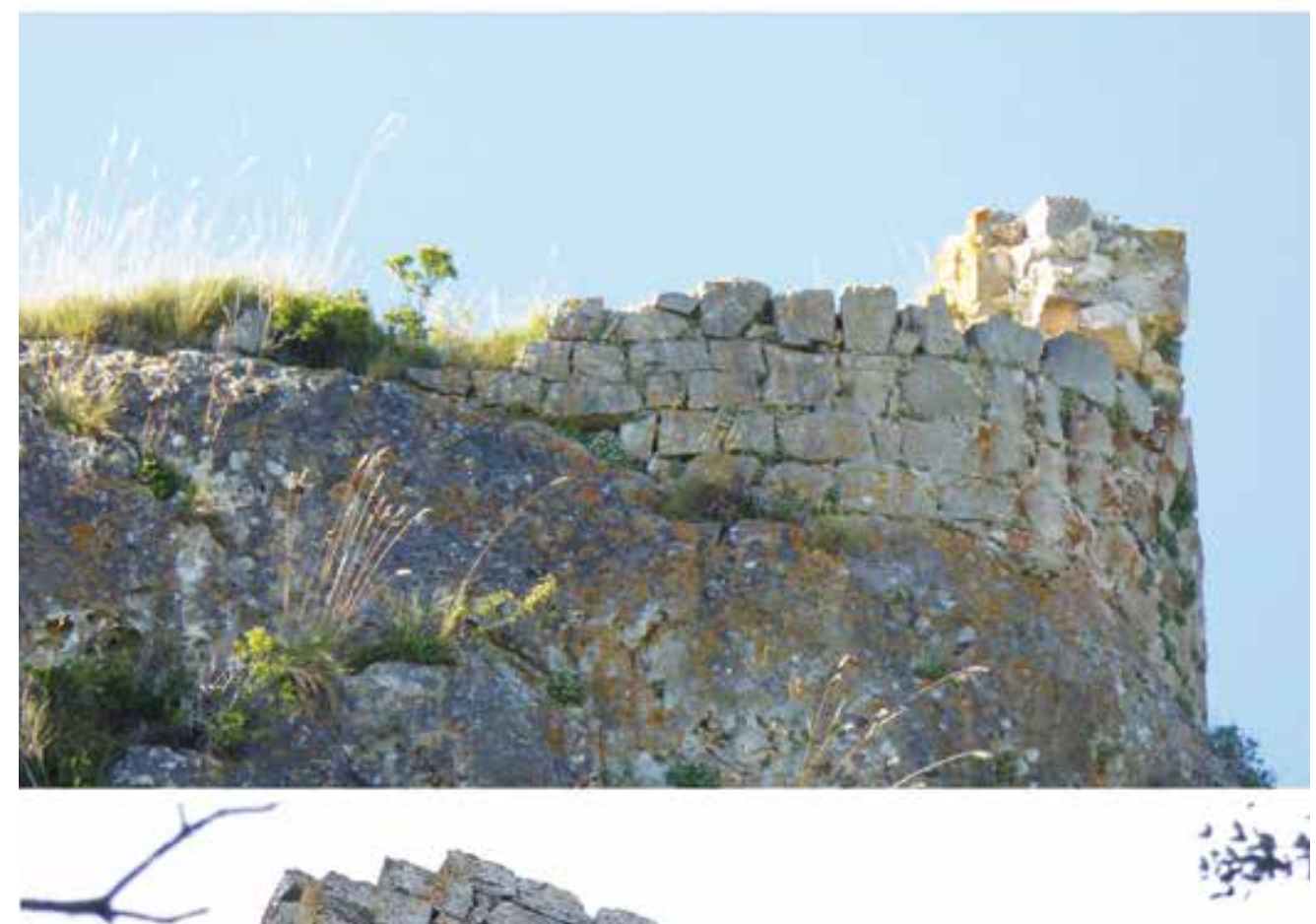

Fig. 5. Detalle de similitud entre aparejos en la torre de poniente (1), la torre del ho-
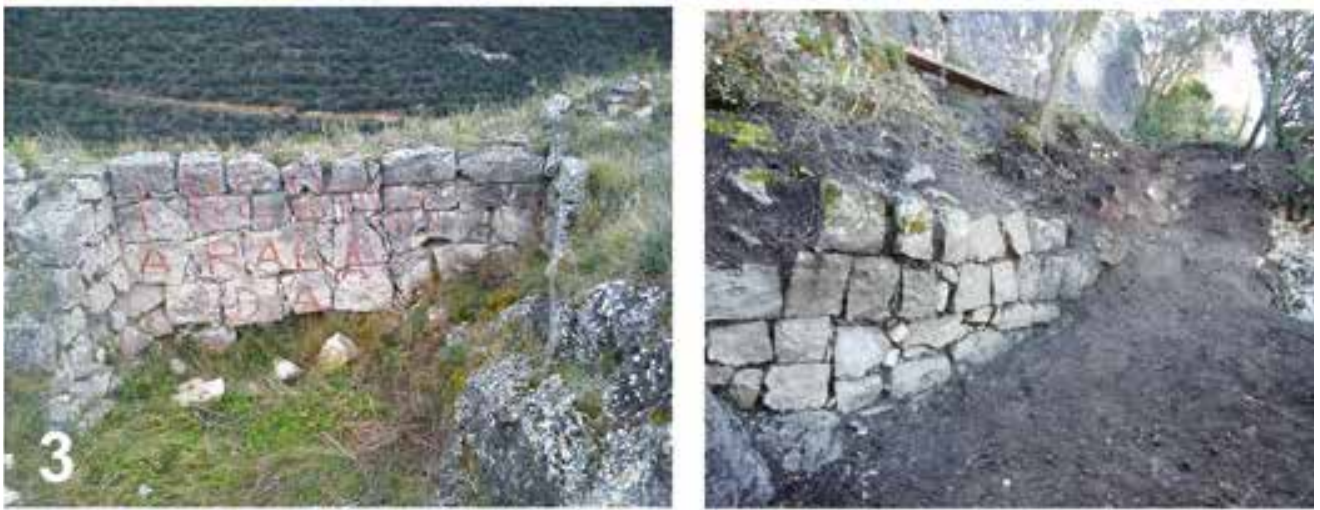
menaje (2), la fragua (3) y la puerta norte y terraza intermedia (4). Todos responden al Tipo 1, caracterizado por el empleo del sillarejo, de mediano y/o gran tamaño, con pequeñas lajas intercaladas entre las hiladas, a modo de ripios./ Detail of similarity in brickwork between the western tower (1), the keep (2), the forge (3) and the north door and the intermediate terrace (4). All belong to Type 1 , characterised by the use of medium and/or large-sized ashlar, with small slabs inserted between the rows. 
queñas lajas intercaladas entre las hiladas de sillarejo, a modo de ripios. En las estructuras principales, como la torre del homenaje (A12) o la terraza intermedia (A15), el modulo se hace mayoritariamente grande, siendo reforzado en los esquinales con sillería labrada a tallante y cincel.

En lo que al mortero se refiere, los análisis mineralógicos denunciaron la existencia de cinco grupos distintos, si bien todos ellos presentaban una misma naturaleza a nivel de áridos, constituidos por granos de cuarzo, bioclastos, fragmentos de roca carbonatada y restos de roca parcialmente calcinados (PONCE, 2014). Esta circunstancia, unido a la existencia de morteros diferentes en actividades iguales $\mathrm{y}$, al contrario, de morteros iguales en actividades diferentes (Tabla 1), hizo que interpretáramos la diversidad de morteros, no tanto como el resultado de diferentes fases constructivas, sino como de diferentes cuadrillas trabajando en un mismo proyecto relativamente complejo.

Especialmente significativo fue también el dato proporcionado por la herramienta de labra empleada en la roca, de cara principalmente a dar verticalidad al farallón rocoso donde se asienta el castillo y mejorar así su defensa. A pesar de que en determinadas zonas había desaparecido por efecto de la erosión, su impronta es perfectamente visible en el foso (A13) y la base del torreón oriental (A11), donde se reconoce el empleo uniforme del picón o puntero. Otro dato revelador fue constatar que la base del mencionado torreón fue realizada de manera simultánea a las rozas y entalladuras abiertas en el suelo de la estancia A1, evidenciando su contemporaneidad.

\begin{tabular}{|l|c|l|}
\hline \multicolumn{1}{|c|}{ ACTIVIDAD } & UE & \multicolumn{1}{c|}{ MORTERO } \\
\hline 6. Aljibe & 31 & Tipo 4. Heterométrico arenoso \\
\hline 17. Terraza intermedia & 30 & Tipo 2. Heterométrico \\
\hline 7. Plataforma superior & 16 & Tipo 5. Heterométrico muy arenoso \\
\cline { 2 - 3 } & 29 & Tipo 1. Homométrico \\
\hline \multirow{2}{*}{ 10. Fragua } & 20 & Tipo 2. Heterométrico \\
\cline { 2 - 3 } & 21 & Tipo 2. Heterométrico \\
\cline { 2 - 3 } & 28 & Tipo 1. Homométrico \\
\hline 11. Torreón oriental & 19 & Tipo 4. Heterométrico arenoso \\
\hline 12. Torre del homenaje & 3 & $\begin{array}{l}\text { Tipo 3. Heterométrico con grandes fragmentos } \\
\text { de roca }\end{array}$ \\
\cline { 2 - 3 } & 4 & $\begin{array}{l}\text { Tipo 3. Heterométrico con grandes fragmentos } \\
\text { de roca }\end{array}$ \\
\hline 14. Torreón de poniente & 1 & $\begin{array}{l}\text { Tipo 3. Heterométrico con grandes fragmentos } \\
\text { de roca }\end{array}$ \\
\cline { 2 - 3 } & 2 & Tipo 2. Heterométrico \\
\hline
\end{tabular}

Tabla 1: Tabla de equivalencias de morteros. / Table of mortar equivalence.
Del estudio combinado de estas variables pudo inferirse, en consecuencia, que las principales estructuras de la fortaleza de Portilla pertenecían a una única fase constructiva, al margen de la heterogeneidad constatada en la plataforma superior (A7) y a la que ya se ha hecho referencia ${ }^{11}$. El conjunto de rasgos técnico-formales que caracterizan a esta fase son: el aparejo de sillarejo de buen tamaño organizado en hiladas regulares; el refuerzo de los esquinales con sillares labrados a tallante y cincel; los morteros conformados por áridos de cuarzo, bioclastos, fragmentos de roca carbonatada y restos de roca parcialmente calcinados; y labra de la roca a picón o puntero.

Las cuatro analíticas radiocarbónicas efectuadas en la materia orgánica (carbón) de los morteros de la torre del homenaje (A12) y la torre de poniente (A14) ofrecieron dataciones análogas (Tabla 2), en una horquilla cronológica que puede situarse entre los primeros decenios del siglo XI y los años centrales de la centuria siguiente.

\subsection{Su abandono y destrucción}

La destrucción y expolio de la fortaleza puede documentarse en el registro arqueológico gracias a las interfaces de robo observables en las diferentes partes de la fábrica descritas anteriormente y a través también de los diversos depósitos conservados en distintos lugares del conjunto.

La excavación arqueológica, por ejemplo, permitió documentar varios estratos de color marrón-grisáceo, de mediana o baja compactación y textura arenosa, caracterizados por la abundante presencia tanto de material

\begin{tabular}{|c|c|c|c|c|}
\hline SECTOR & REFERENCIA & $\begin{array}{c}\text { CÓDIGO } \\
\text { LAB. }\end{array}$ & $\begin{array}{c}\text { EDAD C-14 } \\
\text { (ANNOS BP) }\end{array}$ & $\begin{array}{c}\text { EDAD CALIBRADA } \\
\text { (AÑOS CAL AD) }\end{array}$ \\
\hline \multirow{7}{*}{ Castillo } & $\begin{array}{c}\text { UE 1 } \\
\text { Torreón de poniente }\end{array}$ & CNA2700 & $948+-34$ & $1022-1159(1.000 \%)$ \\
\cline { 2 - 5 } & $\begin{array}{c}\text { UE 2 } \\
\text { Torreón de poniente }\end{array}$ & CNA2701 & $898+-35$ & $1038-1213(1.000 \%)$ \\
\cline { 2 - 5 } & $\begin{array}{c}\text { UE 3 } \\
\text { Torre del homenaje }\end{array}$ & CNA2702 & $920+-35$ & $\begin{array}{l}1027-1189(0.998 \%) \\
1199-1201(0.002 \%)\end{array}$ \\
\cline { 2 - 5 } & $\begin{array}{c}\text { UE 4 } \\
\text { Torre del homenaje }\end{array}$ & CNA2703 & $948+-35$ & $1021-1161(1.000 \%)$ \\
\hline \multirow{7}{*}{ Villavieja } & $\begin{array}{c}\text { UE 1006 } \\
\text { Muralla alta oeste }\end{array}$ & CNA2704 & $975+-35$ & $\begin{array}{l}997-1005(0.017 \%) \\
1011-1155(0.983 \%)\end{array}$ \\
\cline { 2 - 5 } & $\begin{array}{c}\text { UE 1015 } \\
\text { Muralla baja este }\end{array}$ & CNA2705 & $997+-35$ & $\begin{array}{l}981-1056(0.644 \%) \\
1076-1154(0.356 \%)\end{array}$ \\
\cline { 2 - 5 } & $\begin{array}{c}\text { UE 1016 } \\
\text { Muralla baja este }\end{array}$ & CNA2706 & $966+-36$ & $1013-1160(1.000 \%)$ \\
\hline
\end{tabular}

Tabla 2: Relación de fechas carbono-14 realizadas en el yacimiento de Portilla. La calibración se realizó empleando el programa CALIB REV7.0, a dos sigmas $(95,4 \%)$. / List of carbon-14 dating at the Portilla site. The calibration was performed using the CALIB REV7.0 program at 2-sigma (95.4\%).

\footnotetext{
${ }^{11}$ Esta plataforma presentaba múltiples arreglos que, debido a su complicada identificación y delimitación, no permiten ser considerados como fases constructivas.
} 
constructivo procedente de los alzados del castillo (en especial piedra y mortero), como de basura doméstica (restos óseos animales y cerámica). En ocasiones, da la impresión incluso de que algunos de estos rellenos estuvieron destinados a regularizar el paso y facilitar el desmantelamiento de las estructuras de fábrica del castillo.

En cuanto a la horquilla cronológica en la que cabe encuadrar este proceso de abandono y expolio, algunos datos parecen apuntar a los siglos XV y XVI: el estudio de la cerámica recuperada en uno de los rellenos de amortización de A8, por ejemplo, permite datar este depósito a lo largo del siglo XV y la centuria siguiente ${ }^{12}$. Asimismo -y aunque en los rellenos que se extendían por el pasillo inferior A4 se detectó numeroso material cerámico residual (consecuencia de los aportes de tierra secundarios procedentes del desmantelamiento superior del castillo)-, la ausencia total de producciones esmaltadas permite fecharlos siempre con anterioridad al siglo XVII (ESCRIBANO, 2014), datación que va en línea con la propuesta para A8.

En síntesis, es posible deducir que el abandono del castillo de Portilla se efectuó entre el siglo XV y los primeros decenios del siglo XVI, abandono que fue seguido por un proceso de expolio, quizás continuado a lo largo del tiempo, como es práctica habitual en la mayoría de fortalezas abandonadas.

\section{LA VILLAVIEJA}

\subsection{El recinto amurallado}

A los pies del castillo, por el norte, se extiende la antigua villa medieval de Portiella o Portilla de Ibda (popularmente conocida como Villavieja), protegida por unos imponentes estratos verticales de roca caliza que se complementan al este y oeste por sendas murallas de fábrica (Figura 6a). Tras la intervención arqueológica se puso al descubierto más de una treintena de metros de la muralla alta occidental, ocultos durante siglos por un voluminoso estrato de piedra suelta. Aunque apenas conservaba 2 metros de alzado máximo, permitió poner al descubierto el primitivo portal de acceso a la Villavieja por este costado y dos torreones defensivos. Se trataba de una estrecha puerta de apenas 2,2 metros de luz, destinada al paso de personas y animales, que aún conserva uno de los huecos donde iba encajado el alamud de cierre (Figura 6b).

Con estos nuevos datos puede decirse ya que la muralla alta de poniente tenía un recorrido total de aproximadamente 113 metros lineales y cerca de 8 metros de altura, estando jalonada regularmente por cinco torreones semicirculares; dos de ellas protegían la puerta abierta en su costado meridional, siguiendo un esquema clásico de portal torreado documentado en varias villas medievales del entorno. Su fábrica, muy homogénea en todo su recorrido, se caracteriza por presentar un aparejo de mampostería careada con módulo cuadrangular/rectangular de tamaño medio/ grande, dispuesta en hiladas regulares, con presencia alterna de lajas en posición oblicua, producto quizás de paulatinas refacciones. Por momentos muestra también algunos pequeños ripios a modo de lajas. Mantiene un grosor uniforme de 1,80 metros. En muchas partes de su alzado aún conserva restos de un revestimiento de color ocre.

Sabemos que las estructuras recién descubiertas estaban ya ocultas al menos desde el siglo XVIII, puesto que, fines de la centuria, el cartógrafo Tomas López describe la muralla occidental de la Villavieja (ya despoblada) con "tres torreones o cubos" (ALTARRIBA, 2000: 237), sin registrar los dos torreones exhumados en las recientes excavaciones arqueológicas. La importancia de estos descubrimientos es aún mayor, ya que existía la creencia errónea (también desde al menos el siglo XVIII) de que la puerta al poblado se situaba en el extremo septentrional de la muralla, en el lugar donde se abren dos grandes huecos, producto realmente del expolio al muro.

La lectura estratigráfica efectuada sobre todo el cinturón defensivo permitió comprobar una gran homogeneidad entre el aparejo de la muralla alta occidental y la muralla baja de oriente, apreciación ésta corroborada posteriormente por los resultados de los análisis radiocarbónicos. Estos análisis, efectuados a la materia orgánica presente en los morteros de varios puntos de la muralla proporcionaron fechas BP muy similares que, al ser calibradas, ofrecieron una horquilla cronológica situada entre fines el siglo $X$ y la primera mitad del siglo XII d.C. (Tabla 2).

Hay que apuntar, sin embargo, que ambas murallas presentan algunas diferencias derivadas de su situación topográfica. La muralla baja de oriente carece de torreones, innecesarios desde el punto de vista defensivo por su privilegiada situación en fuerte pendiente. Su grosor tiende paulatinamente a disminuir a medida que la muralla asciende por la ladera sur, pasando de 1,7 metros en el extremo meridional hasta 1,4 metros en el extremo opuesto (Figura 6e). Es posible adivinar además la ubicación del viejo portal de acceso, ya que se conserva uno de los huecos del alamud de cierre en el extremo norte de la muralla. Aunque resulta imposible conocer su luz, por estar el umbral oculto por un relleno de tierra y piedra, cabe imaginar que pudiera ser similar a la registrada en la muralla alta, aunque, a diferencia de aquella y tal y como acabamos de decir, en este caso carecería de torreones.

\footnotetext{
${ }^{12}$ Cronología propuesta atendiendo a la ausencia de cerámica esmaltada y a los porcentajes registrados de cerámica vidriada (26\%) y sin vidriar (74\%) (Escribano, 2014).
} 

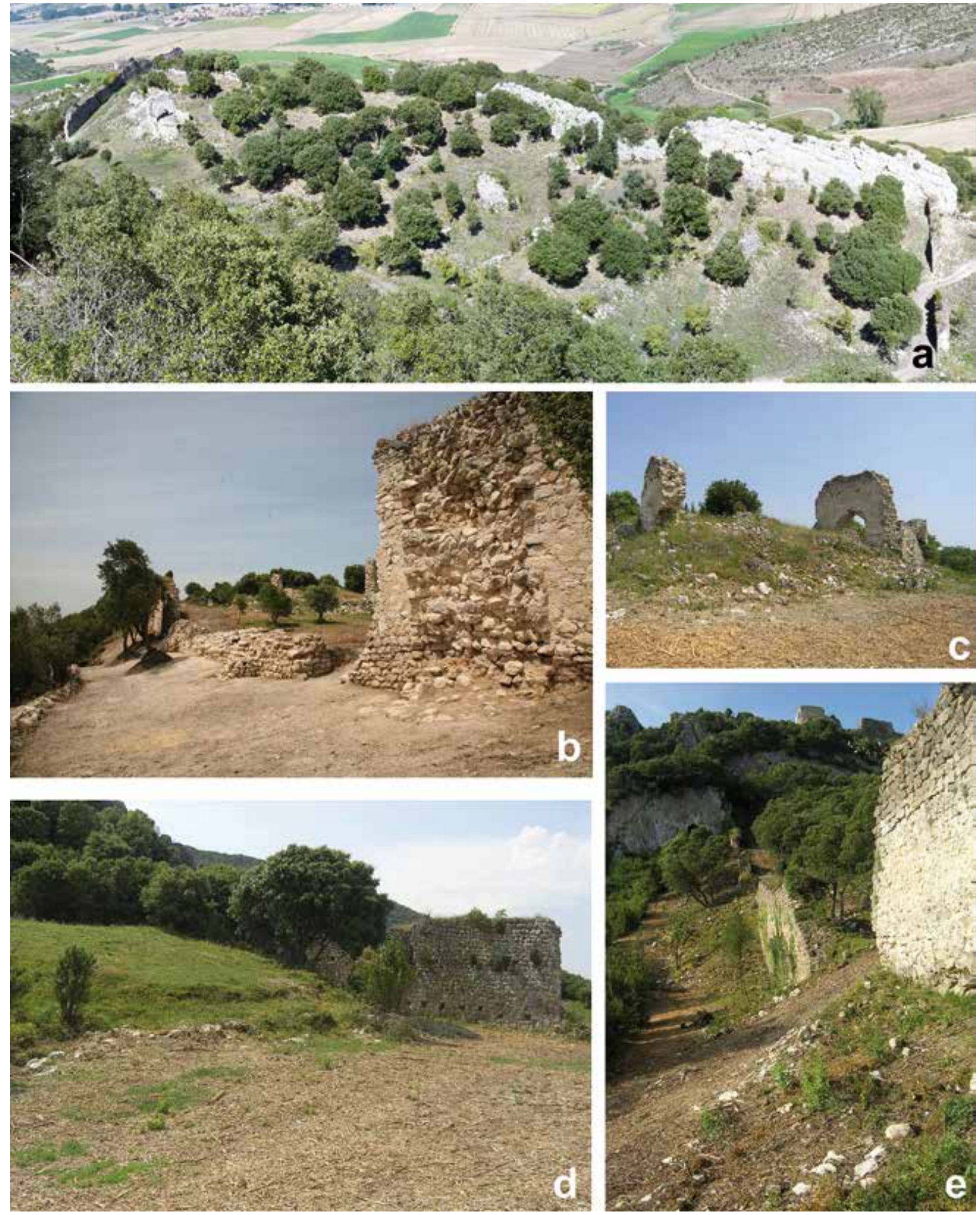

Fig. 6. a) Vista de la Villavieja con el sistema de terrazas agrícolas implantado en la $2^{\mathrm{a}}$ mitad del siglo XVl: b) Imagen de la muralla alta occidental descubierta tras la intervención arqueológica; c) Estado actual de la ermita de Santa María; d) Espacio intramuros junto la murara alta. Obsérvese, a la izquierda, el nuevo camino habilitado tras la conversión de la Villavieja en campos de cultivo; e) Vista extramuros de la muralla baja oriental./ a) View of the "Villavieja" with its agricultural terrace system, implemented in the second half of the 16th century; b) Image of the western high wall, uncovered in the archaeological process; c) Current state of the Santa Maria chapel; d) Space between the walls adjacent to the external wall. Note, on the left, the new path that was opened after the "Villavieja" was converted into farmland; e) External view of western courtyard. 


\subsection{Abandono y reconversión en campos de cultivo}

Todo apunta a que el abandono definitivo de la Villavieja se efectuó hacia mediados del siglo XVI. Sabemos por un documento de "Concordia entre las villas de Portilla y Berganzo" datado en 1530 que, a diferencia de esta última localidad, Portilla nombra dos procuradores generales (Martín Sáenz de Estavillo y Diego López de Tobera) que, a su vez, eligen como juez árbitro para los pleitos con Berganzo a Fernán García, cura clérigo beneficiado de la iglesia de Santa María de Portilla (ALTARRIBA, 2000: 247). Cabe inferir de ello la existencia todavía de dos poblaciones en Portilla, la Villavieja y el actual pueblo de Portilla, con sendos procuradores y una sola parroquia en la Villavieja.

Algunos años más tarde sin embargo, en 1540, comienza la construcción de la iglesia en el arrabal (dedicada al Salvador) y sólo dos años después, en 1542, el obispo de Calahorra da licencia para que la parroquia se traslade desde la primitiva iglesia de Santa María (que quedará convertida en ermita) a la recién construida del Salvador en la actual Portilla (ECHEVERRIA, VÉLEZ, 2011: 457) y, junto con la parroquia, muy probablemente también lo pocos vecinos que aún habitaban la Villavieja, integrando el barrio jurídicamente dependiente de los Velasco, señores de la fortaleza de Portilla y una parte (uno de los barrios) del pueblo de Portilla ${ }^{13}$.

Tras el abandono de la Villavieja, su viejo trazado urbano fue cubierto por toneladas de tierra destinadas a crear un sistema de terrazas agrícolas que se ha mantenido hasta la actualidad. Para ello se procedió a la construcción de diversos muros de aterrazamiento y a la deposición de potentes paquetes de tierra que amortizaban casi todo el espacio intramuros ${ }^{14}$ (Figura 6a). La amortización del viejo poblado obligó a habilitar un nuevo camino de acceso a las diferentes parcelas agrícolas, en posición más alta que éstas, localizado a los pies de la ladera Norte del castillo, de dirección Este-Oeste. Este camino, de aproximadamente 2,5 metros de anchura, es aún visible en algunos puntos de su recorrido, especialmente en su extremo occidental, donde se sitúa un nuevo paso abierto en la muralla (Figura 6d).

Aunque aún no se ha cometido la excavación arqueológica del poblado, es lógico pensar a que dicho proceso debió emprenderse hacia la segunda mitad del siglo XVI, inmediatamente después del total abandono de la Villavieja ya descrito. Por otra parte, aunque el material cerámico recuperado en esta actividad muestra importantes tasas de residualidad (resultado de los aportes de tierra secundarios procedentes del entorno), es nuevamente significativa la ausencia de producciones esmaltadas, circunstancia que permite fechar el contexto con anterioridad al siglo XVII.

\section{DISCUSIÓN}

A pesar de ser un elemento fácilmente identificable en el paisaje y de larga tradición historiográfica en el País Vasco, el castillo ha pasado desapercibido hasta hace pocos años en la historiografía sobre la configuración de la sociedad feudal de nuestro territorio. Y ello pese a que varios de ellos habían sido objeto de intervención arqueológica desde muy temprano (SOLAUN et alii, 2009). Preocupados por temas relacionados con los orígenes sociales de la Reconquista y la historia política de los reinos cristianos, los investigadores han incidido tradicionalmente sobre otros aspectos como la importancia de estas fortalezas en la defensa de los espacios fronterizos, primero frente a los ataques musulmanes de los siglos VIII y IX d.C., y después en las continuas luchas entre los reinos de Castilla y Navarra.

Este enfoque, excesivamente reduccionista, ha comenzado a ser superado cuando la historiografía arqueológica ha incorporado al debate otros marcos interpretativos relacionados fundamentalmente con el papel que jugaron los castillos en la formación de la sociedad feudal. Desde esta óptica, se acepta hoy en día que los castillos pudieron desempeñar funciones muy diversas -no necesariamente sincrónicas (residencia de los poderes locales, jerarquización y articulación del territorio, concentración de la población, etc.)- como queda reflejado en la propia heterogeneidad formal de las fortificaciones y en la variabilidad de situaciones históricas que conocieron.

Sin embargo, la debilidad del registro arqueológico (unido a la escasez de noticias escritas) hace que contemos con pocos datos para comprender de manera más precisa el papel que jugaron. Como se señalaba recientemente, a pesar de haberse intervenido en un número importante de fortalezas, las intervenciones han sido muy reducidas en extensión y no han sido muy pródigas en el análisis de sus registros y en la difusión de los resultados, lo que dificulta la consecución de un cuadro de síntesis sobre la arqueología de los castillos de época alto y plenomedieval en el País Vasco (QUIROS, 2012).

Resulta, por lo tanto, fundamental disponer de registros arqueológicos de calidad, con referencias cro-

\footnotetext{
${ }^{13} \mathrm{El}$ actual pueblo de Portilla se hallaba singularmente dividido, desde al menos el siglo XVII, en dos barrios con jurisdicciones distintas, aunque físicamente no había más separación que una línea de mojoneras, en medio de la cual estaba la casa consistorial y cárcel, junto con el horno que era común a ambos barrios, lo mismo que la iglesia. Uno de los barrios pertenecía al señorío de los Velasco (Condestables de Castilla y duques de Frías), mientras que el otro se encontraba en régimen de proindiviso entre los Gauna (que, posteriormente, por herencia mudaría a los Ayala y López de Ábalos) y los Zamudio (que por vía matrimonial pasó a los Guevara).

${ }^{14} \mathrm{~A}$ mediados del siglo XIX aún se mantenían en uso algunas de estas terrazas agrícolas, aunque en franca regresión (actualmente no hay memoria de ello), según se deduce de una noticia histórica que apunta como sus "calles solitarias y sombrías hemos visto sembrar diversas veces" (SALOMON, 1857).
} 
nológicas precisas que coadyuven a la construcción de relatos sólidos desde la propia especificidad del yacimiento, para después asentar -sobre bases firmes- discursos que permitan su futura contextualización en un marco de referencia más amplio (TEJADO, 2012). Creemos que nuestras investigaciones en la fortaleza de Portilla se orientan en esta dirección, aportando datos precisos sobre sus orígenes y su desarrollo posterior.

Sabemos que la ocupación humana en Portilla puede remontarse a época protohistórica, si bien no será hasta el siglo XI cuando se registre la existencia de una fortaleza en el lugar. Su historia escrita arranca en el año $1040^{15}$, cuando el rey pamplonés García Sánchez III otorga la carta de arras a su mujer doña Estefanía de Foix. Entre las posesiones entregadas se mencionan determinados lugares bajo su autoridad, entre ellos el castrum de Portilla: "atque alio senior Fortuni Sancii cum ips terra que tenet uel castros, Buradon et Portiella ac Maragnione atque Laquion cum omni herentia eorum" (RODRIGUEZ R. DE LAMA, 1992: 24-26).

La importancia de este documento es máxima para conocer qué era Portilla en el año 1040. Por un lado, se reconoce su condición de castillo, avalada por su designación (junto a Buradón y Marañón) como "castrum", se indica también la presencia de un territorio - "omni herentia eorum"-; y se alude, finalmente, al complejo juego de relaciones existente entre el poder público (el rey) y el poder privado (los barones del reino) por el control de la fortaleza.

1. Sabemos, por tanto, que en el año 1040 Portilla poseía una fortaleza. Ahora bien, ¿cuál fue su origen?, ¿es posible identificar esta fortaleza con las estructuras actualmente conservadas? Con el objetivo de dar respuesta a estas interrogantes y a otras nacidas en el contexto del proyecto de recuperación de Portilla, se procedió al estudio arqueológico del castillo. Como principal conclusión de estos trabajos podemos decir que nos encontramos antes una construcción -ejecutada con técnicas de carpintería, albañilería y canteríaque se articulaba en tres niveles de altura, configurando un conjunto edificado en un mismo momento histórico y en una única fase constructiva. Los análisis radiocarbónicos realizados la torre del homenaje y el torreón de poniente proporcionaron una datación análoga, entre los primeros decenios del siglo XI (post. a 1020) y mediados del siglo XII.

Esta horquilla cronológica -aún con todas las reservas que aconsejan estos casos- permite proponer para la construcción del castillo un fecha que transcurriera entre el año 1020 (postquem aportado por el C14) y el año 1040 (antequem aportado por la documentación escrita $)^{16}$.

Aunque en el estado actual de la investigación resulta difícil aportar más datos en este sentido, la construcción del castillo puede ponerse en relación con un proceso general de fundación de fortalezas registrado a partir de la segunda mitad del siglo $X$ y el siglo XI en el País Vasco. Cada vez parece más clara la emergencia de un "grupo" de castillos en nuestro territorio a partir de estas fechas (Peña Castillo, Untzueta y Ereño son algunos ejemplos claros) que, atendiendo a funciones y motivaciones diversas, fueron levantados combinando técnicas constructivas de carpintería, albañilería y cantería. Un grupo que podría identificarse -siguiendo la sugerencia de J.A. Quirós- con los "castillos de tercera generación" (QUIROS, 2012).

2. Con relación a su titularidad, las evidencias apuntan a que la fortaleza fue propiedad pública, al menos, desde el siglo XI. Esto no significa que no debamos considerar la posibilidad de una iniciativa señorial previa (aceptando, obviamente, la hipótesis de una fortificación anterior al siglo XI) o, incluso, que el control por parte del poder real pueda ser anterior, sino que es en esta centuria y la siguiente cuando tenemos certeza de ello. Así lo sugiere, principalmente, la mencionada carta de arras de García Sánchez III (a. 1040) y las permutas de Portilla a lo largo del siglo XII, realizadas mediante pactos firmados entre los monarcas navarros y castellanos, que finalizarán en el año 1200 con la entrega definitiva del lugar a Alfonso VIII (ORELLA, 2011).

Este hecho no implica, sin embargo, que el control efectivo de la fortaleza estuviera en manos del rey. Como se desprende también de la citada carta de arras, el castrum de Portilla es entregado a su mujer, doña Estefania de Foix, perteneciente a una de las familias más importantes de la aristocracia francesa; pero, a su vez, se encontraba gobernado por dos seniores, Diego Sánchez y Fortún Sánchez III, ambos miembros destacados de la nobleza pamplonesa. La mención a señores o representantes de los reyes en Portilla continúa en los años siguientes, con más de 30 referencias hasta 1199, fecha de la última mención (Ibidem).

En consecuencia, aunque el castillo de Portilla formara parte del patrimonio real, se encuentra en manos de importantes aristocracias regionales, principalmente navarras; sin olvidar que en el año 1040 se entrega como dote a la reina Estefania de Foix. Todo lo cual no hace sino ahondar en las complejas relaciones existen-

\footnotetext{
${ }^{15}$ Existe otro documento fechado en el año 934, que la mayoría de historiadores consideran una falsificación de época posterior. Nos referimos al famoso documento de los votos del Conde de Castilla Fernán Gonzalez, en el que menciona determinados lugares bajo su autoridad, para que pagasen al monasterio de San Millán una porción de "vino en oblatione, et singulos panes en offerta", entre ellos Portilla: "...et Portella, istae praedictae cum omnibus suis villis ad suas alfoces...".

${ }^{16}$ Siguiendo esta hipótesis y partiendo, como desarrollaremos más adelante, de que la fortaleza de Portilla fue de titularidad real, su construcción cabría atribuírsela al monarca pamplonés Sancho Garcés III el Mayor(1004-1035) o a su hijo García Sánchez III (1035-1054), opciones muy plausibles atendiendo al contexto sociopolítico de ambos monarcas, embarcados en un proceso general de expansión y fortalecimiento del reino de Pamplona en el condado de Castilla.
} 
tes entre el poder público y privado que, en muchas ocasiones, hace complicado identificar en quien recae el verdadero control de estas fortalezas.

3. En lo que respecta a su funcionalidad, los castillos desempeñaron múltiples usos que no tuvieron por qué ser simultáneos, sino que fueron variando a lo largo del tiempo, al compás del desarrollo de nuevas estrategias productivas y de la sucesión de los acontecimientos políticos y sociales. Como ya se ha dicho, Portilla fue mucho más que una fortaleza. Comprendía también un territorio en el que se integraba la antigua villa de Portiella, en una estrecha relación entre castillo y núcleo habitado sobre cuya naturaleza y origen debe investigarse todavía ${ }^{17}$. En este sentido, llama poderosamente la atención la analogía de fechas entre la construcción del castillo y las murallas de la villa. Las dataciones radiocarbónicas realizadas en las murallas alta y baja de este enclave proporcionaron una horquilla cronológica prácticamente igual a la del castillo, comprendida entre los primeros decenios del siglo XI (post. a 1010) y mediados del siglo XII (Tabla 2). Las estadísticas derivadas de la calibración efectuada a las muestras radiocarbónicas ofrecen un porcentaje (60\%) que apoyan su construcción en la primera mitad del siglo XI. Sea como fuere, de lo que no hay duda es que su amurallamiento se efectuó con anterioridad a mediados del siglo XII, cuando menos en fechas similares a núcleos alaveses tan relevantes como Gasteiz o Salinas de Añana, dando idea de la entidad de este enclave, no sólo como fortaleza, sino también como centro urbano.

De su consideración como probable central place dan muestra también las fuentes escritas de los siglos $\mathrm{XI}$ y XII, de las que cabe inferir, sin demasiados problemas, la consideración de Portilla con un centro administrativo del reino de Pamplona, lo que la historiografía ha venido en llamar una tenencia. Sin entrar a debatir los orígenes de este modelo de organización social del espacio, lo cierto es que Portilla aparece dando nombre a una circunscripción del sistema administrativo navarro desde el siglo XI, condición que mantuvo hasta finales del siglo XII, cuando el territorio se encontraba dividido en 56 distritos (Ibidem: 195) ${ }^{18}$.

El registro escrito reconoce también diferentes tenentes o representantes del rey al frente de Portilla. No obstante, como apunta Álvarez Borge (2008: 250-256), una tenencia es una realidad más amplia que abarca casi siempre a más de un individuo, en un cuadro jerárquico que puede alcanzar hasta tres niveles: tenentes, subtenentes (estos últimos representados mayoritariamente en la figura del alcaide) y sub-subtenentes.

Aunque en Portilla carecemos de referencias documentales a alcaides o subtenentes, es razonable supo- ner su existencia. Por un lado, porque el registro escrito muestra la acumulación de tenencias en manos de un mismo señor -como en los casos de Fortún Sánchez III, señor de Portilla, Buradón, Marañón y Peñacerrada en el año 1040, o de Garcia Petri de Morieta, señor de Portilla y Treviño en 1192 (PESCADOR MEDRANO, 1999)-, de donde se deduce que algunas de ellas tuvieron que estar forzosamente en manos de subtenentes. Y, por otro lado, porque las reducidas dimensiones de las diversas estancias del castillo, con una torre del homenaje de apenas $12 \mathrm{~m}^{2}$ de superficie, no invitan a imaginarlo como residencia habitual de importantes barones de la nobleza navarra.

Por todo ello, y enlazando con la propuesta de Álvarez Borge, resulta más razonable situar en Portilla a delegados de rango inferior (pertenecientes posiblemente a aristocracias locales) que serían percibidos por la población como los verdaderos agentes para su defensa y gobierno, quedando los grandes señores como representantes del rey a nivel supralocal. Una prueba más, en definitiva, de la complejidad de relaciones de dependencia entre los diferentes poderes sociales.

Sabemos también, como ha quedado reflejado ya en las páginas precedentes, que Portilla estuvo relacionada con la defensa de los espacios fronterizos. La plaza de Portilla será pieza clave hasta el siglo XIII en la fijación de la frontera entre castellanos y navarros, con diferentes vaivenes políticos hacia un lado u otro. Son varias las noticias en este sentido, relacionadas en su mayor parte con permutas conseguidas mediante pactos firmados entre las partes. En el año 1076 Portilla se encuentra bajo influencia del rey de Castilla Alfonso VI, aunque pocos años después, en 1085, la fortaleza tenía nuevamente como seniores a representantes del rey de Pamplona, concretamente a D. Diego Sanchez y su hermano D. Iñigo (ORELLA, 2011). Desconocemos el momento concreto en que Portilla pasó nuevamente a manos castellanas, aunque ya lo estaba en el año 1177. No obstante, dos años después, el rey Alfonso VIII entregaba a Sancho VI de Navarra la plaza de Portilla. De esta manera, Portilla pasaba nuevamente a formar parte del sistema administrativo navarro. Como adelantamos más arriba, el final de estos vaivenes políticos llegará en el año 1200, momento en que el rey Alfonso VIII devuelve a Navarra Miranda de Arga a cambio de Portilla, que quedará definitivamente anexionada a la corona de Castilla.

Tras la anexión castellana todo apunta a que fue la influyente casa de Haro quien se hizo con el control de la fortaleza, en recompensa muy posiblemente por los servicios prestados a Alfonso VIII y sus sucesores. El juego de poderes entre el rey y sus barones alcanza cotas máximas de tensión en estos momentos, hasta el punto

\footnotetext{
${ }^{17} \mathrm{~A}$ día de hoy desconocemos los orígenes del poblamiento medieval de Portilla y, por ende, si el asentamiento ya existía con anterioridad al castillo o, por el contrario, fue coetáneo a él.

${ }^{18}$ Entre ellas, además de Portilla, se encontraban lugares tan importantes como Estella, Laguardia, Olite, Roncesvalles, Sangüesa, Uxue, Tafalla o Vitoria.
} 
de que Portilla y otras plazas fuertes pueden considerarse ya verdaderos centros de dominio señorial, eludiendo tácitamente el control real. La campaña de luchas del año 1288 entre el monarca Sancho IV y Diego Lopez IV de Haro en diferentes fortalezas del territorio, entre ellas Portilla, es un claro ejemplo de esta situación. Una situación que denuncia la diversidad de condicionantes políticos, sociales y económicos que influyeron en la creación y desarrollo de estas fortalezas a lo largo del tiempo.

\section{AGRADECIMIENTOS}

Este trabajo ha sido posible gracias al proyecto de recuperación del Conjunto Monumental de Portilla, financiado por el departamento de Educación, Política Lingüística y Cultura del Gobierno Vasco (Subvenciones para la defensa, enriquecimiento, protección y fomento del Patrimonio Cultural Vasco. Orden del 21/12/2011; Resolución del 01/10/2012); el departamento de Agricultura, Pesca y Alimentación del Gobierno Vasco (Programa LEADER. Expediente $n^{\circ}$ 11-2012-00357) y el Ayuntamiento de Zambrana. Queremos mostrar también nuestro agradecimiento a la Diputación Foral de Álava.

Agradecemos, finalmente, a los evaluadores de la revista MUNIBE y a Jose María Tejado la lectura del texto y sus comentarios, que han ayudado sin duda a mejorar el trabajo.

\section{BIBLIOGRAFIA}

\section{ALTARRIBA, A. (Coord.)}

2000 Doscientos años de geografía en Álava. Del cuestionario de Tomás López a la actualidad. Vitoria-Gasteiz.

\section{ALVAREZ BORGE, I.}

2008 Cambios y alianzas. La política regia en la frontera del Ebro en el reinado de Alfonso VIII de Castilla (11581214). Madrid

\section{AZKARATE, A.}

1997 Consideraciones de carácter metodológico sobre el estudio de las complejos rupestres alaveses. Primer Encuentro Nacional de Estudio de Cavidades artificiales. Valencia. 137-158.

2010 El análisis estratigráfico en la restauración del patrimonio construido, Arqueología Aplicada al estudio de edificios históricos. Últimas tendencias metodologicas. Madrid. 51-65.

\section{AZKARATE, A., SOLAUN, J.L.}

2008 Peña del Castillo (Marquínez). Arkeoikuska 2007, 62-67.

2012 Tipologías domésticas y técnicas constructivas en la primitiva Gasteiz (País Vasco) durante los siglos VIII al XII d.C. Arqueología de la Arquitectura 9, 103-128.

2013 El registro arqueológico, en AZKARATE, A., SOLAUN, J.L., Arqueología e historia de una ciudad. Los orígenes de Vitoria-Gasteiz, Tomo I, 75-91. Bilbao.
CARANDINI, A.

1997 Historias en la tierra. Barcelona.

ECHEVERRIA, P.L., VELEZ, J.J.

2011 Parroquia de la Santísima Trinidad (Portilla), en TABAR, F. (coord.). Catálogo Monumental de la Diócesis de Vitoria, Los valles occidentales entre el Zadorra, el Ayuda $y$ el inglares, Tomo X. 457-466. Vitoria-Gasteiz.

\section{ESCRIBANO, S.}

2014 Genealogía del registro cerámico alavés de época preindustrial (siglos XIV al XVII). Tesis doctoral inédita.

\section{FERNANDEZ BORDEGARAI, J.}

1991 Castillo y despoblado de Portilla (Zambrana, Álava), Informe. Sondeo arqueológico 1991, Informe inédito de resultados.

2007 Portilla de Ibda: Evolución Histórica de una fortaleza durante los conflictos navarro-castellanos de los siglos $\mathrm{XI}$ y XII, en Actas de las Jornadas Congresuales "Homenaje a Micaela Portilla". 405-414. Vitoria-Gasteiz.

MARTÍNEZ TORRES, L. M.

2014 Reconocimiento geológico del castillo de Portilla (Zambrana, Álava). Informe inédito.

ORELLA, J.L.

2011 Nacimiento de Gipuzkoa como tenencia navarra de frontera. Lurralde 34, 189-217.

\section{PESCADOR MEDRANO, A.}

1999 Tenentes y tenencias del Reino de Pamplona en Álava, Vizcaya, Guipúzcoa, la rioja y Castilla (1004-1076). Vasconia 29, 107-144.

PONCE, G.

2014 Caracterización arqueométrica y problemática asociada a la datación por radiocarbono de los morteros arqueológicos procedentes del Castillo de Portilla (Alava). Trabajo de Fin de Máster inédito.

QUIROS, J.A.

2011 L'eccezione che conferma la regola? Incastellamento nella valle dell'Ebro nel $X$ secolo: il Castelo di Treviño. Archeologia Medievale XXXVIII, 113-136.

2012 1911-2011: Un siglo de excavaciones arqueológicas en los castillos medievales del País Vasco, en QUIROS, J.A., TEJADO, J.M. (eds). Los castillos altomedievales en el noroeste de la Península Ibérica. 123143. Bilbao.

QUIROS, J.A., TEJADO, J.M. (Eds.)

2012 Los castillos altomedievales en el noroeste de la Península Ibérica. Bilbao.

\section{RODRIGUEZ R. DE LAMA, I.}

1992 Colección diplomática Medieval de la Rioja, Tomo II. Logroño. 
SALOMON, R.

1857 La antigua plaza de armas de Portella. Semanario Pintoresco Español, 11-12.

SANCHEZ, I., SOLAUN, J.L.

2003 Excavaciones en el Castillo de Ocio (Ocio, Álava). Arkeoikuska 2002, 209-220.

SOLAUN, J.L., GARCÍA CAMINO, I., MORAZA, A., RAMOS, M.

2009 Arqueología del Feudalismo. Un recorrido historiográfico por la arqueología de época medieval y moderna en el País Vasco y Navarra (ss. XI-XVIII), en LLANOS, A. (coord.). Actas del Congreso Internacional Medio siglo de arqueología en el Cantábrico Oriental y su entorno. 501-550. Vitoria-Gasteiz.

SOLAUN, J.L., GAZTELU, U., ORTEGA, L.A., RODRIGUEZ, J., MORILLO, A., ABECIA, A.

2014 Group of monuments of Portilla (Basque Country, Spain). A project about comprehensive management of heritage. Preservation, Maintenance and Rehabilitation of Historical Buildings and Structures, Vol. I. 387-398. (REHAB 2014).

TEJADO, J.M.

2012 ¿A modo de conclusiones... o mejor, agenda de trabajo?, en QUIROS, J.A., TEJADO, J.M. (Eds.). Los castillos altomedievales en el noroeste de la Península Ibérica, 309-320. Bilbao. 